\title{
Durability of fine-grained limestone concrete
}

\author{
Vladimir Belov ${ }^{1}$, Temur Barkaya ${ }^{2 *}$ and Pavel Kuliaev ${ }^{2}$ \\ ${ }^{1}$ Department of Construction materials and technologies, Tver State Technical University, Tver, \\ Russia \\ ${ }^{2}$ Department of structures and facilities, Tver State Technical University, Tver, Russia
}

\begin{abstract}
Production of effective building materials of high-density and high-durability is connected with the development of methods of modification of such materials on macro-, micro- and nanostructural levels. Presently the application of finest ingredients in admixture compositions such as limestone filler produced from local quarries is viewed as a primary task of cost reduction in limestone concrete manufacturing. The efficiency of limestone filler to enhance the durability of fine-grained limestone concrete is shown in tests performed. Limestone half inert filler conjointly with superplasticizer are found to enhance crack-resistance and reduces creep strains, which makes fine-grained limestone concrete the most effective and long-standing material. Knowledge of the stress-strain distribution in concrete with limestone fines under compression is important for the design of certain kinds of reinforced thin-walled concrete structures, such as shells, membranes and domes. These structures are manufactured with addition of both limestone filler and superplasticizer performing synergetic effect which leads to increasing a level of crack causing stresses.
\end{abstract}

\section{Introduction}

Processed limestone crushed rocks from local quarries is widely used to upgrade certain application properties of fine-grained concretes, such as durability, crack-resistance and vitality [1]. Fine-grained limestone concrete as a composite construction material is inhomogeneous solid material consisting of two or more components: reinforcing elements and a binding matrix. From the very beginning of its wide application there have been made attempts to obtain analytical dependences between the durability of the concrete and particles distribution in the admixtures. Limestone powder is best and cheapest substitute to other hard aggregates, such as granites. Limestone filler is considered to be one of the best modifier of chemical and technological properties of fine-grained limestone concrete and a replacement of a binder [2]. This is due to the ability of limestone powder to work jointly with clinker ingredients in a concrete body [3] which consists of the fluid matrix of water, binder, various water-reducing admixtures and skeleton of inner structure filled with aggregates and fillers. Physical and chemical compatibility of limestone fine grains and filler with cement as a partial replacement of it comes from the properties of limestone fine particles to facilitate distribution of the granular cluster more smoothly within the concrete

\footnotetext{
* Corresponding author: btrs@list.ru
} 
volume, perform micro-reinforcement of a mineral skeleton of concrete and affect the hydration process by delaying closest contacts with cement [4]. On the basis of previous researches [5] these all are likely to improve durability features, strain capacity of concrete, reduce long-time creep [6] and thereby contribute to enhance crack-resistance and durability through densest grain packaging and optimal grading.

\section{Experiment}

\subsection{Apparatus}

The studies were carried out in Tver Technical University to reveal enhancing durability and crack-resistance of fine-grained limestone concrete as related to water-cement ratio, cement to limestone ratio, an amount of superplasticiser. Ten concrete cubes of 7x7x7 sm. have been tested in compression. Limestone filler is a by-pass well-sewed product of jawcrushed limestone rocks. Aggregates were also limestone grains ranging from 5 to 0.05 mm.

Durability, crack-resistance and instant strains of fine-grained limestone concrete were analyzed on a special frame (Fig 1.).

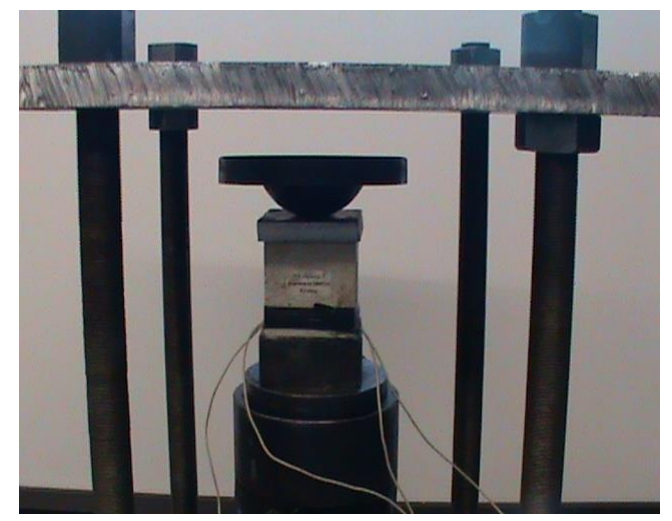

Fig. 1. Test frame and specimen with electrical gauges on its two sides.

\subsection{Technics}

Crack appearance has been fixed with electrical strain gauges. Measurement precision was $10^{-7}$. To determine crack resistance, an appropriate reduced stress intensity coefficient was used, which took into proper account specific features of concrete as heterogeneous, composite material with complex structure of minute invisible cracks and a big trunk crack.

$$
\begin{aligned}
& \boldsymbol{K}_{r}=\left(1-\mu^{2}\right) \times K_{l}^{2} / E \\
& K_{l}=\sigma \times \sqrt{\pi \times l}
\end{aligned}
$$

$K_{r}-$ reduced stress intensity coefficient, $\mathrm{MPa} \times \mathrm{sM}$

$K_{l}-$ cross-sectional method stress intensity coefficient, $\mathrm{MPa} \times \mathrm{SM}^{1 / 2}$

$l$-trunk crack half-width,

$\mu$ - Poisson coefficient, taken equal to 0.3 ,

$\sigma$ - crack-causing stress,

$E$ - elasticity modulus.

The following is the table with the mixture compositions. 
Table 1. Mixture compositions, $\mathrm{kg}$ per $1 \mathrm{~m}^{3}$.

\begin{tabular}{|c|c|c|c|c|c|c|}
\hline $\begin{array}{c}\text { No. } \\
\text { mixtures }\end{array}$ & binder, $\mathrm{kg}$ & aggregates, $\mathrm{Kg}$ & cement, $\mathrm{kg}$ & $\begin{array}{c}\text { Water- } \\
\text { cement } \\
\text { ratio }\end{array}$ & $\begin{array}{l}\text { Limestone } \\
\text { filler, } \mathrm{kg}\end{array}$ & SP-1, кg \\
\hline 1 & 672 & 1528 & 672 & 0.47 & 0 & 0 \\
\hline 2 & 672 & 1528 & 336 & 0.45 & 336 & 0 \\
\hline 3 & 672 & 1528 & 672 & 0.39 & 0 & 5.04 \\
\hline 4 & 672 & 1528 & 672 & 0.34 & 0 & 6.72 \\
\hline 5 & 672 & 1528 & 672 & 0.37 & 0 & 3 \\
\hline 6 & 672 & 1528 & 472 & 0.46 & 200 & 0 \\
\hline 7 & 672 & 1528 & 472 & 0.41 & 200 & 2.11 \\
\hline 8 & 672 & 1528 & 553 & 0.39 & 119 & 4.15 \\
\hline 9 & 672 & 1528 & 336 & 0.43 & 336 & 0.89 \\
\hline 10 & 672 & 1528 & 336 & 0.41 & 336 & 2.52 \\
\hline
\end{tabular}

The following is the table 2 with the test results.

Table 2. Compression test results.

\begin{tabular}{|c|c|c|c|c|c|c|}
\hline $\begin{array}{c}\text { No. } \\
\text { compos } \\
\text { ition }\end{array}$ & \multicolumn{2}{|c|}{$\begin{array}{c}\text { Crack stress and } \\
\text { strength in } \\
\text { compression }\end{array}$} & $\begin{array}{c}\text { Relative strain } \\
\xi\end{array}$ & $\begin{array}{c}\text { Elastisity } \\
\text { modulus } \\
\text { E, MPa }\end{array}$ & $\begin{array}{c}K_{l}, \\
\mathrm{MPa} \times \mathrm{SM}^{1 / 2}\end{array}$ & $\begin{array}{c}K_{r}, \\
\mathrm{MPa} \times \mathrm{sm}\end{array}$ \\
\hline 1 & 34.4 & 44.1 & 0.0025 & 17640 & 19.28 & 0.00099 \\
\hline 2 & 23.3 & 27.8 & 0.0087 & 3195.4 & 13.06 & 0.00372 \\
\hline 3 & 31.5 & 42.6 & 0.002 & 21300 & 17.66 & 0.00075 \\
\hline 4 & 36.7 & 48.5 & 0.0019 & 25526.32 & 20.57 & 0.00073 \\
\hline 5 & 31.9 & 43 & 0.0063 & 6825.4 & 17.88 & 0.00238 \\
\hline 6 & 28.2 & 35.6 & 0.0021 & 16952.38 & 13.56 & 0.00085 \\
\hline 7 & 34.1 & 41.2 & 0.0025 & 16480 & 19.11 & 0.00106 \\
\hline 8 & 40.1 & 46.8 & 0.0021 & 22285.71 & 22.48 & 0.00092 \\
\hline 9 & 30.3 & 37.3 & 0.0033 & 11303.03 & 16.98 & 0.00137 \\
\hline 10 & 30 & 37.1 & 0.0028 & 13250 & 16.81 & 0.00115 \\
\hline
\end{tabular}

The values of reduced stress intensity coefficient $K_{r}$ for limestone containing specimens are greater than for the specimens without limestone filler.

Limestone fines and superplasticizer act synergetically and give birth to certain plastic zones at the main trunk crack and depriving it of the energy to progress. Dynamic viscosity also increases. That is the essence of the conjoint mechanism of crack restriction via limestone and superplasticizer SP-1.

The following figures illustrates correlation between strength in compression, reduced stress intensity coefficient $K_{r}(\times 1000)$, limestone fines content, limestone filler content and water-cement ratio.

Optimal amount of limestone powder as a partial replacement of binder is 17-18\%.

Limestone filler somewhat reduced the compressive strengths of concretes when it was used to replace cement, but instant strains are seemed to be lower for the specimens with limestone powder. 


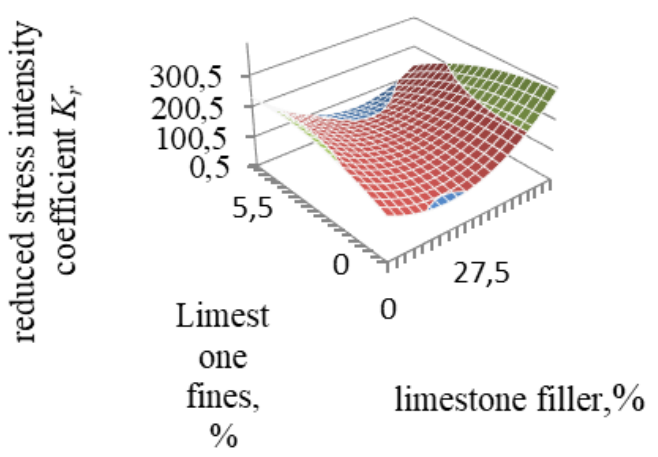

Fig 2. Correlation between reduced stress intensity coefficient $\mathrm{Kr}$, amount of limestone fines and limestone filler.

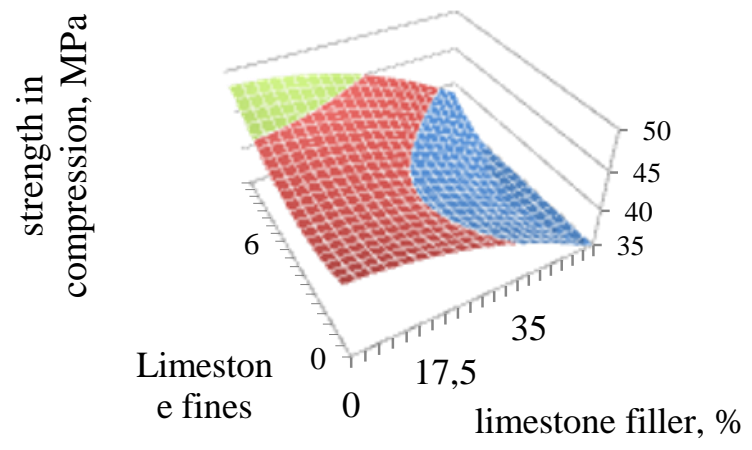

Fig 3. Correlation between strength in compression, limestone fines content and limestone filler.

The use of limestone powders as a partial replacement of cement also require the use of a superplasticiser to compensate the loss of strength due to higher air-entraining and microporosity level [7]. In tests superplasticiser SP-1 was used in optimal amount of $0,75 \%$ of cement volume. The following is the graph of compressive strength versus amount of limestone filler in paste.

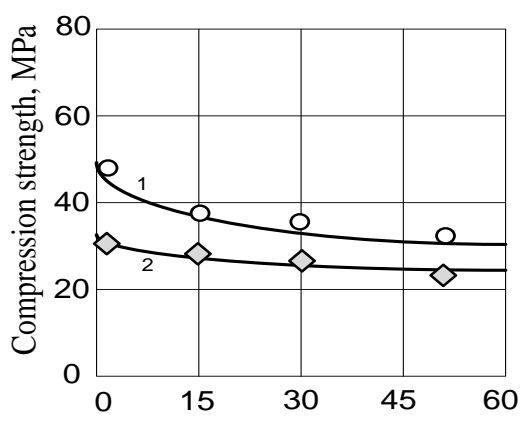

Limestone filler content, $\%$ of cement

Fig 4. Compression strength - curve 1 and crack stresses - curve 2 versus limestone filler content in a composite of limestone fine-grained concrete. 
We can see that the gaps between crack-stresses and strength values are narrower for the specimens containing limestone powder. This is owing to better distribution of the cement particles and filling in air and capillary pores [7,8]. It enhances hydration, makes the paste more smooth and promotes uniform consolidation of the composite.

Optimal amount of superplasticizer needs to cover up the exceeding amount of superfine limestone particles that increase an air-entraining and slacken pore-free consistency of cement paste.

Increasing the amount of fine powders requires an increase in the superplasticizer dosage for stabilizing hydratation, which can conversely affect the short-term development of both strain and strength.

The following chart depicts the measured values of instant strains versus limestone filler and SP-1 content.

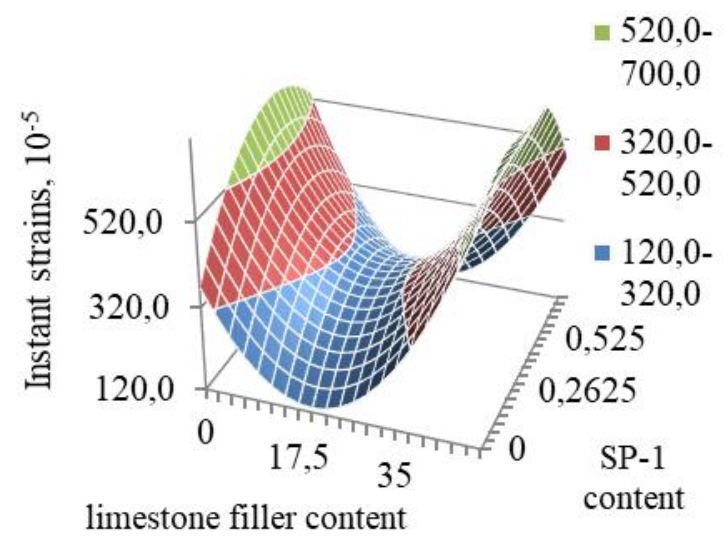

Fig 5. Instant strains versus limestone filler and SP-1 content in a composite of limestone fine-grained concrete.

The values of the instant strains indicate the better strain capacity of the specimens with limestone addition, as compared to that of specimens without it. Positive role of limestone fines in enhancing durability, crack-resistance and vitality of limestone fine-grained concrete is beyond any doubts.

\section{Summary and prospects}

A complex additive to concrete made of limestone filler and superplasticizer SP-1 is probed to have positive role as far as durability features of limestone fine-grained concrete is concerned.

Limestone filler being manufactured within local quarries provides good efficiency and cheap replace for cement. Easily ground limestone powder usually has a wide range of particle size distribution which promotes during processing filling ultra-voids between the cement particles, thus reducing the water demand, improving the homogeneity of mortar and uni-forming microstructure of cement paste. This results in enhanced durability and crack-resistance, without essential loss in technological properties, which indicate greater values of stress intensity coefficient $\mathrm{Kr}$ for limestone containing specimens. Instant strain values are obviously smaller for these specimens too. Enhanced durability of limestone fine-grained concrete also comes from better packing of particles within the concrete 
matrix. Reduction in porosity is viewed to be caused by micro-cracks transference from air and capillary areas into sub zones.

Further prospects for improving durability indexes of limestone fine-grained concrete are believed to be connected with the application of some "wise" materials, new-brand hyperplasticizers and nano-level entraining simulating techniques [9].

\section{References}

1. S.P. Sivkov. Current trends in cement production in Russia. Russian Yearbook, p.p.76-80 (2011)

2. V.G. Khozin, O.V. Khokhrya-kov, I.R. Sibgatullin. Carbonate cements with low water demand. Technologiya betonov, 11-12, p.25 (2009)

3. G. De Schutter. Effect of limestone filler as mineral addition in self-compacting concrete. Belgium Magnel laboratory of concrete research, (36 Conference on Our World in concrete \& Structures, Singapore, 14-16/08/2011)

4. I.V. Gorynin, P.A. Kuznetsov. Structural and functional nanostructured materials. Nanotechnologii, ekologiya, proizvodstvo, 1(8), p.p. 116-121 (2011)

5. B. Moser, C. Pfeifer. Microstructure and Durability of Ultra-High Performance Concrete. (Proceedings of the Second International Symposium on Ultra High Performance Concrete Kassel, Germany March 05-07, 2008)

6. P. Desnerck, G. De Schutter, L. Taerwe. Stress-strain behavior of self-compacting concretes containing limestone fillers. Ernst\&Sohn, Structural concrete, 13(2) (2012)

7. V.V. Belov, M.A. Smirnov. Theoretical basis of methods of optimization of granulometric composition of the formulation of the compositions for the manufacture of chemically bonded construction conglomerates. Russian Academy of architectural and construction Sciences. Bulletin of the Department of construction Sciences. Scientific publication, 15, p.p.175-179 (Moskva-Orel-Kursk. 2011)

8. V.V. Belov, I.V. Obraztsov, T.B. Novichenkova. Capillary Structure Formation of Raw Composites Based on Mineral Binding Substances. Nanotechnologies in Construction: Scientific Internet-journal, 4 (8), p.p.23-36 (2010)

9. Y. D. Tretiakov. Evolutsiya nanomaterialov. Nanoparticles, nanostructures and health problems. Nanotechnologii, ekologiya, proizvodstvo, 1(8), p.p. 98-106 (2011) 